\title{
Correction to: Effectiveness and acceptance of a web-based depression intervention during waiting time for outpatient psychotherapy: study protocol for a randomized controlled trial
}

\author{
Sasha-Denise Grünzig ${ }^{1 *}$, Harald Baumeister ${ }^{2}$, Jürgen Bengel ${ }^{1}$, David Ebert ${ }^{3}$ and Lena Krämer $^{1}$
}

\section{Correction}

Following publication of the original article [1], the author reported the errors in the figure and in text reference in the published article. These errors are detailed below. The original article has been corrected.

1. Figure 2 SPIRIT-figure appears in the manuscript although it is only meant as online supplementary material.

2. In the Design section, the citation for the supplementary online materials should be "Additionally, Fig. 2 (SPIRIT-figure) and File 1 (SPIRIT-checklist) are available online" instead of "Fig. 2 and Additional file 1 are available online".

\section{Author details}

${ }^{1}$ Department of Rehabilitation Psychology and Psychotherapy, Institute of Psychology, Albert-Ludwigs-University Freiburg, Engelbergerstr. 41, 79085 Freiburg, Germany. ${ }^{2}$ Department of Clinical Psychology and Psychotherapy, University of UIm, Albert-Einstein-Allee 47, 89081 UIm, Germany.

${ }^{3}$ Department of Clinical Psychology and Psychotherapy, Institute of

Psychology, Friedrich-Alexander University Erlangen-Nürnberg, Nägelsbachstr. 25a, 91052 Erlangen, Germany.

Published online: 19 July 2018

\section{Reference}

1. Grünzig SD, et al. Effectiveness and acceptance of a web-based depression intervention during waiting time for outpatient psychotherapy: study protocol for a randomized controlled trial. Trials. 2018;19(1):285. https://doi.org/10.1186/s13063-018-2657-9.

\footnotetext{
* Correspondence: sashi.gruenzig@psychologie.uni-freiburg.de 'Department of Rehabilitation Psychology and Psychotherapy, Institute of Psychology, Albert-Ludwigs-University Freiburg, Engelbergerstr. 41, 79085 Freiburg, Germany

Full list of author information is available at the end of the article
}

(c) The Author(s). 2018 Open Access This article is distributed under the terms of the Creative Commons Attribution 4.0 International License (http://creativecommons.org/licenses/by/4.0/), which permits unrestricted use, distribution, and reproduction in any medium, provided you give appropriate credit to the original author(s) and the source, provide a link to the Creative Commons license, and indicate if changes were made. The Creative Commons Public Domain Dedication waiver (http://creativecommons.org/publicdomain/zero/1.0/) applies to the data made available in this article, unless otherwise stated. 